\title{
Application of 3D documents in the land cadastre: problems of legal regulation
}

\author{
Maria Zakharova*1 \\ ${ }^{1}$ Lomonosov Moscow State University, Moscow, Russia, zakharovamari@ya.ru
}

\begin{abstract}
The article considers the use of 3D documents in electronic document management and land cadastre. Earth audit (cadastre) within the "Digital Earth" is carried out through 3D documents. The technical nature of 3D documents is clear, but the legal regime is quite complex and poorly understood. In this situation, it is impossible to conduct an audit of the Earth through a 3D document without establishing its legal regime. This article identifies possible ways to develop domestic legislation in the field of digitalization on the example of a 3D document and makes suggestions for improving the current legislation and defining the legal regime of a $3 \mathrm{D}$ document, including in relation to the land cadastre.
\end{abstract}

\section{Keywords}

3D document, visualization, digitalization, digital economy, electronic document management, digital audit, Earth audit, land cadaster.

\section{Introduction}

In the process of transition of the economy of developed countries to the sixth technological stage, the formation of the noonomics, there is an active introduction of information technologies in all spheres of human activity.

The development of visualization technologies and the spread of the Internet have given rise to a completely new type of information landscape that combines not only signs and symbols, but also visual images. Combining different types of information that reflect aspects of external reality in different ways can radically change the perception of the world by persons.

The formation of the economy of mind (noonomics) leads to a wider spread of ways to capture information in the form of a 3D model, and, consequently, the transition to 3D documents. ${ }^{1}$

This new type of document allows you to implement in practice the possibility of all-course, i.e. the most complete and complete, representation of geospatial objects.

Today, a lot of documentation is being converted to digital form: organizational and administrative, accounting and technical. The state cadastre system is also developing and widely applies modern information technologies. It also provides online services.

For example, all Internet users have access to the public cadastral map, a reference and information service designed to provide users with information about the State real estate cadastre

\footnotetext{
Corresponding author

1 Baturin, YuM, Eremchenko EN, Zakharova MI (2019) 3D-document and Digital Earth. CEUR Workshop Proceedings. Vol. 2485. pp. 155-158.
} 
on the territory of the Russian Federation. With the help of this system, the user can get reference information about the full cadastral number, address and area of the land plot entered in the State real estate cadastre without leaving home. The location of land plots is fixed by entering the flat coordinates of their borders in the cadastre. This system allows you to consider the area and configuration of plots, but the terrain is overlooked due to the two-dimensional (plane) of the modern cadastre. ${ }^{2}$

With the development of urban infrastructure, two-dimensional registration of real estate objects is losing its relevance. Modern buildings are primarily characterized by multi-level buildings. Highways, subways, various utilities, residential and administrative buildings can be located at different heights of the same land plot (including above and below ground). Current circumstances require that modern cadastral systems support 3D geometric and topological models and, as a result, use 3D documents in their work.

A 3D model allows you to store the spatial characteristics of an object (geometry, texture, structure, and others) in a three-dimensional coordinate system associated with the object. This property qualitatively distinguishes it from photo and film shooting, which preserve only twodimensional images of the object. ${ }^{3}$

A 3D document is specially organized information designed to present the user with a threedimensional (spatial) visual image (3D model) of an object or process, as well as a variety of additional information based on this visual image.

The increasing creation and use of digital 3D models of real objects and processes to save on them resulted in no such thing as a 3D document that is used in the scientific literature for over a decade.

A special feature of the structure and image of a 3D document is that they can be stored as a point or polygon model. For example, as a result of laser scanning, a point cloud is formed, which is a text file in which each line determines the position of one point in space $(\mathrm{x}, \mathrm{y}, \mathrm{z}$ coordinates in a certain coordinate system). When these points are simultaneously displayed on a computer in threedimensional space, they "contour" the object's surface, allowing the viewer to see a virtual 3D point model of the object.

The geometric accuracy of such a model can reach thousandths of a percent of the object size.

\footnotetext{
Pavlova EA (2012) Development of three-dimensional cadastre of real estate objects in Russia (Russian). Young scientist. $8(43), 40-42$

3 Eremchenko E, Tikunov V, Nikonov O, Moroz V, Massel L, Zakharova A, Dmitrieva V, Panin A (2017) Digital Earth and digital economy (Russian) Geocontext. No5. T. 5. pp. 48-57
} 
However, since it is not able to provide photorealistic visualization and is not convenient for analysis, polygonal 3D models are often built on its basis, including textured ones that preserve geometric accuracy with varying degrees of coarsening. The surface of an object in a polygon model is defined by a set of polygons, which are polygons, usually triangles. ${ }^{4}$

\section{Discussion}

Using virtual 3D models allows you to capture and save a qualitatively larger amount of information about the spatial characteristics of an object, unlike other methods. This advantage is most pronounced when working with large objects that have a complex geometry and spatial structure. In this regard, the use of digital 3D models is becoming more widely used, especially in the development of scientific and technical documentation.

While remaining an electronic document, a 3D model of an object can be linked by mutual links to other types of object (text, audio, and video files), including on remote servers accessed via the Internet.

From a technical point of view, a 3D document is information organized in a special way that is intended to present the user with a three-dimensional visual image of an object or process, as well as additional information obtained from this visual image.

Considering the format of a 3D document, it should be noted that in addition to the fact that it allows for a much more complete fixation of information about the geometry, structure and appearance of an object, its use allows the user to independently "explore" the object.

This "research" allows you to view the 3D model from different angles, change the display parameters, and study additional information related to the visual image.

3D modeling allows you to accurately reproduce and sometimes recreate objects that have already been lost in order to preserve them for future generations. Domestic developments in the field of $3 \mathrm{D}$ documentation of unique objects are conducted at the center for the virtual history of science and technology of the Vavilov Institute of history of natural science and technology of the Russian Academy of Sciences (IHST RAS).

An example of such developments is the project on laser scanning and 3D modeling of the Shukhov tower on Shabolovka, which was carried out as part of the development of the permanent

\footnotetext{
4 Eremchenko EN, Tikunov VS (2016) Holographic visualization capabilities in geography (Russian). Bulletin of the
} Moscow University. Series 5: Geography. N. 2. pp. 22-29. 
exhibition of achievements of the Russian Academy of Sciences.

To create such a 3D model of the tower in 2011. a laser scan of the structure was performed, which recorded the geometry of the structure with high accuracy and spatial resolution. A polygonal 3D model was created based on the point cloud obtained as a result of scanning, the accuracy of which was about $1 \mathrm{~cm}$ in a single coordinate system (with a tower height of $160 \mathrm{~m}$ ).

An example of 3D documentation of a natural object is the project "Virtual Valley of geysers", which was implemented with the support of the Russian Foundation for basic research. This valley is located in the Kronotsky reserve in Kamchatka - one of the largest geyser fields in the world and a unique natural object. The decision to create a virtual 3D model of the valley was made after a catastrophic landslide occurred in 2007, which changed the terrain of the territory and destroyed part of the geysers.

As a result of the work, a high-resolution model of the territory was created, which was later implemented on a virtual globe. Information about this unique natural object was saved as a set of 3D models and an associated information system, which can be considered an example of a developed 3D document. ${ }^{5}$

The increase in the number of tunnels, pipelines, underground parking lots, bridges, overpasses, structures on stilts and other high-rise multi-level buildings are precisely the factors that relegate two-dimensional registration systems to the background and show the advantages of a complex of structured environments in which integrated use of space prevails.

The introduction of a three-dimensional approach in such areas as laser scanning, spherical panoramas, and 3D geoinformation system clearly demonstrates the technological feasibility of a three-dimensional cadastral system.

The three-dimensional inventory is already used and applied in 24 EU countries. The state cadastre of the Netherlands stands out, with an efficient cadastral system and a functioning real estate market. This inventory is professionally maintained and is almost flawless in both theoretical and practical terms. Such an innovation could improve the cadastral system in Russia. ${ }^{6}$

Land law in the Netherlands is governed by civil law. According to the type of cadastral registration, the Netherlands can be attributed to the system of registration of documents (notarial acts), supported by one organization: the Agency for cadastre, land registration and cartography of the Netherlands Kadaster, which is an independent and financially completely independent

\footnotetext{
5 Leonov AV, Baturin YuM (2014) 3D Document - a new type of scientific and technical documentation (Russian). Bulletin of the Archivist, N 2. pp. 192-205.

6 Nikolaeva TV, Nikitin VN (2014) Cadastre in 3d format (Russian). Interexpo Geo-Siberia. Vol. 2. pp. $199-204$.
} 
organization since 1994. Unlike in Russia, where the main units of the cadastre include land plots, buildings, structures, premises and objects under construction, in the Netherlands only land plots are subject to cadastral registration. Information about the legal status of buildings or structures can be obtained from the rights registered on surface areas, and the notarial act required for registration can be accompanied by an analog image of the physical object. Dutch law sets mandatory requirements for determining three-dimensional boundaries when registering premises. ${ }^{7}$

In Russia, work has already been carried out on the development of a three-dimensional real estate cadastre. In 2012, the Russian-Dutch project "Creating a model of a three-dimensional real estate cadastre in Russia" was completed.

The project was developed by the Federal service for state registration, cadastre and cartography, the Federal cadastral center "Earth", the Agency for cadastre, land registration and cartography of the Netherlands (an advanced European organization), the Dutch companies GrontmijNederland, RoyalHaskoning and the technical University of Delft.

The Nizhny Novgorod region was identified as the pilot region for the project, where several pilot sites were selected on the territory of Nizhny Novgorod. The project was implemented from May 2010 to June $2012 .^{8}$

Among the pilot objects for which the prototype of the 3D cadastre was developed were the following:

1. Teledom object (9/1 Belinsky street): - multi-level office building with underground Parking, including many premises with various types of registered rights to them. Part of the building overhangs the roadway of the street, while the other part of the building is located above another building located on an adjacent plot of land.

2. Object " multi-apartment residential building " (66A Nevzorovykh str.). A multi-story residential building with a more typical 3D configuration, including 88 residential properties and 7 non-residential buildings. Underground Parking is shared. This object is characterized by many copyright holders, and various types of rights and restrictions are registered: property, lease, etc.

3. The gas Pipeline facility (Piskunov street) is a medium - pressure gas pipeline that includes underground and aboveground parts and is owned by Nizhegorodoblgaz LLC.

To implement these projects, floor plans of buildings were used, and prototypes were created

\footnotetext{
https://vipisca.ru/2015/03/sravnitelnyj-analiz-3d-kadastra.html

8 Kalacheva NI (2013) Application of the 3-D cadastre with a time component in land and property relations of road management (Russian). CAD and GIS. 1, pp. 67-69.
} 
in the GoogleSketchUp software package. ${ }^{9}$

A three-dimensional inventory has several advantages. First, it allows you to get a visual representation of a real estate object while simultaneously displaying various information about this object. Secondly, the three-dimensional cadastre increases the efficiency and validity of decisionmaking in the field of land and property relations, the stability of integrated management of the system of objects, and the transparency of taxation of real estate of citizens and organizations. In addition, this type of inventory creating favorable conditions for investment in the sphere of cadastral relations, significantly increases the rights of property owners and reduces the length of trials and increases the relevance of information contained therein.

But at the same time, there are several legal problems for creating a full-fledged 3D real estate cadastre. In the legislation of the Russian Federation in the field of state registration of rights to real estate and transactions with it, as well as in the field of state cadastral registration, there is no mention of 3D objects and documents that, accordingly, must appear during the creation of a threedimensional cadastre. In this regard, the introduction of a legal definition of a 3D document and the definition of its legal regime is particularly relevant.

Based on the analysis of the current Russian legislation, we can conclude that the 3D document mode is still not formed, since there are no direct rules governing this object. A developed 3D document can combine elements with different legal regimes.

A developed 3D document can combine elements with different legal regimes. For example, the intellectual rights to the created 3D model may be owned by individuals and organizations that are located or registered not only on the territory of the Russian Federation. 3D models can be protected by various intellectual property rights institutions: as objects of copyright, patent law, and the right to means of individualization of legal entities, goods, works, and services. The use of such models and their infrastructure (data, program code) may be regulated by various types of license agreements, such as the GNU GPL, Creative Commons, and others. In this regard, the most important issue is the choice of the legal protection regime for three-dimensional models.

The question of whether these models can be protected as objects of patent law needs to be resolved, and if so, how three-dimensional models should be differentiated, if not, how the interests of patent holders can be protected in connection with the development of 3D printing.

First, it is necessary to reveal the concept of copyright and patent rights. In accordance with

\footnotetext{
Deeva AK, Shirina NV (2016) Three-Dimensional cadastre in the Russian Federation (Russian). Student scientific forum. Belgorod state technological University named after V. G. Shukhov.
} 
Russian civil legislation, the author of any result of intellectual activity is a citizen who created such a result through his creative work.

In cases where the result of intellectual activity was created by two or more citizens through their creative work, the right of authorship belongs to them jointly and is called co-authorship.

The exclusive right arising as a result of such activity may be transferred by the author to another person by entering into a contract or on other grounds, but the direct right of authorship, the right to a name and other non-property rights may not be alienated, and their protection is indefinite.

Exclusive rights may be protected in different ways, including by bringing a claim for recognition to the person who denies or otherwise does not recognize the rights of the author rather than violate its interests, on the suppression of acts infringing the right or creating a threat of its violation, compensation of losses to the person who wrongfully used result of intellectual activity in the absence of agreement with the owner, which could violate the author's right to remuneration.

Speaking about the exclusive right to result of intellectual activity, it should be noted that the citizen or legal person has the exclusive right to result of intellectual activity or means of individualization (the rightsholder) shall have the right to use such result or such means at own discretion any method not contradict the law.

The copyright holder allows or prohibits other persons to use their intellectual property, and the absence of a ban cannot be considered a permission.

Restrictions on exclusive rights to works of science, literature and art, objects of related rights, inventions and industrial designs, and trademarks may be established if they:

- do not contradict normal use and do not unreasonably infringe on the legitimate interests of copyright holders and third parties;

- do not contradict the usual use of inventions or industrial designs (article 1228 of the civil code of the Russian Federation).

The right to use an exclusive right may be granted through a license agreement, according to which one party, the owner of the exclusive right to the result of intellectual activity or the licensor, undertakes to grant or grants to the other party, called the licensee, the right to use such result within the limits provided for in such agreement. Such a contract can only be concluded in writing, failure to comply with which gives grounds to consider the contract invalid (article 1235 of the civil code of the Russian Federation).

The license may be exclusive, in which the licensee is granted the rights to use the results of intellectual activity without retaining the licensor's right to issue licenses to other persons. When the 
licensor reserves this right, the license is referred to as simple or non-exclusive. The licensor itself is deprived of the right to use the result of intellectual activity to the extent that the right to use is granted to the licensee as an exclusive license. But this provision is not mandatory, and the contract may provide for other conditions (article 1236 of the civil code of the Russian Federation).

A person who has undertaken to organize the creation of a complex object that includes several protected results of intellectual activity, for example, a multimedia product, acquires the right to use such results on the basis of agreements on the alienation of an exclusive right or license agreements that such a person enters into with the holders of exclusive rights to the corresponding results of intellectual activity. During the use of the result of intellectual activity as part of a complex object the author of such a result retains the right of authorship and other personal nonproperty rights to such a result (article 1240 of the civil code of the Russian Federation).

Patent rights include intellectual property rights to inventions, utility models, and industrial designs. The authors of such inventions, utility models or industrial designs have the exclusive right and the right of authorship. In addition, the author of an invention, utility model or industrial design also has other rights, including the right to obtain a patent, the right to remuneration for a service invention, utility model or industrial design (article 1345 of the civil code of the Russian Federation).

Copyright protects the form of an intangible object, while patent law is responsible for protecting its content regardless of the form.

If we consider three-dimensional models for 3D printing from this point of view, they are not directly technical solutions protected by patent law. These models can be called a form of expression of the corresponding solutions. Thus, three-dimensional models for 3D printing cannot be objects of patent law. At the same time, the production of goods using 3D printing, which embody, for example, inventions or utility models and industrial designs, as well as their further introduction into civil circulation violates the exclusive right to a patent. The objects of patent rights include the results of intellectual activity in the scientific and technical sphere that meet the established requirements for inventions and utility models, and the results of intellectual activity in the field of design that meet the established requirements for industrial designs.

In the current legislation, the concept of a single technology is closest to the legal regime of a 3D document. A single technology may contain the results of intellectual activity that are not subject to legal protection under patent law, including technical data and other information.

On the one hand, we can conclude that the most appropriate is the copyright regime for 
protecting 3D models for 3D printing, since many countries are fighting Internet piracy at the legislative level.

On the other hand, there is another problem. To be protected by copyright, an object must have a creative character, and the creative character must be inherent in its form.

It is also important to note that the term of protection of copyright objects significantly exceeds the term of protection of patent objects, which may hinder the development of the economy, science and technology.

Thus, we can conclude that the $3 \mathrm{D}$ model needs a qualitatively new mechanism of legal protection, which would combine copyright in relation to the suppression of illegal distribution of objects on the Internet,and more democratic terms of patent protection.

To date, there is not a single legislative act in the domestic legislation that directly regulates issues related to a 3D document. Only a small number of state Standards have been adopted, which only indirectly affect issues related to $3 \mathrm{D}$ documents. In this regard, it is proposed to introduce the concept of a 3D document or 3D model in legislative acts. It is advisable to select a 3D document as an independent object of the protected result of intellectual activity and a means of individualization.

A 3D document cannot be effectively protected either as an industrial design or trademark, or as a database, since it differs significantly from the latter in both the methods of creation and the purposes of use. That is why it needs an independent method of protection and should be included in article 1225 of the Civil code of the Russian Federation.

As an example of recent changes made in this area, which resulted in the allocation of a new object for the protection of intellectual property results and means of individualization, we can cite the recently adopted amendments that introduced such an object as a geographical indication. Such an indication is understood as a designation that identifies a product originating from the territory of a geographical object, a certain quality, reputation or other characteristics of which are largely related to its geographical origin. A geographical indication is recognized as such and placed under protection after its state registration, the exclusive right is certified by a certificate.

By its nature this object is like the appellation of origin of goods, but between them there are several differences, such as the lack of need for a geographical indication to a special property of the product.

This situation has a lot in common with a 3D document and an industrial design, so a 3D document is primarily an external solution, but at the same time it has a number of technical 
characteristics that are not important for determining the novelty of an industrial design.

Therefore, a 3D document needs its own legal protection mechanism. It is advisable to proceed by analogy with databases and programs for electronic computers. A $3 \mathrm{D}$ document must be classified as a copyright object regardless of the method of its creation and the nature of the model, but at the same time it must be possible to register the created 3D model with the state.

Copyright within the meaning of the fourth part of the civil code refers to intellectual rights to works of science, literature and art. Computer programs are works of literature for the purpose of copyright protection. Given the importance of the visual component of a 3D model, it is possible to equate it with a work of art by analogy.

This way, the authors of all 3D documents will get the rights:

1. Exclusive right to a product;

2. Copyright;

3. Author's right to name;

4. Right to inviolability of the work;

5. Right to publish a product.

In addition, the copyright holder will be able to provide more effective protection of their interests in the event of disputes, as well as receive additional income from the sale of licenses.

To register a certificate for a 3D document, you can set the provision of such documents in addition to the application as a brief description of the model with a limit on the number of characters up to seven or five hundred, as well as, by analogy with the registration of an industrial design, a set of 3D model images that will help identify the model and other materials that reveal the essence of the 3D document.

The fee may also be set at the rate of three thousand for individuals. After reviewing the application, the person must also be issued a special certificate certifying their exclusive rights to the $3 \mathrm{D}$ document. It is advisable to create a special Register that considers the rights to 3D models, in which data about registered documents will be entered.

\section{Conclusions}

It is also necessary to amend Chapter 70 of the Civil code, indicating the copyright of the manufacturer of the 3D document, as well as Chapter 71 on related rights, adding a 3D document after the paragraph on the rights of the database manufacturer. 
In addition to changes in legislative acts, it is necessary to develop recommendations for standardizing the use of 3D documents, since the law cannot contain all the issues related to the creation and use of such documents.

Regarding the legal norms, it should be noted that in General, the issues of electronic document management and 3D modeling are not sufficiently regulated by current legislation, and the main part of the norms and definitions is contained in various state Standards. ${ }^{10}$

For example, the General requirements for creating text documents that are already familiar to us are set by state Standard 7.0.97-2016. The concept of an electronic document as a document whose information is presented in electronic form is contained in state Standard R 7.0.8-2013. National standard of the Russian Federation. System of standards for information, library and publishing. Clerical and archival work. Terms and definitions. The closest to $3 \mathrm{D}$ technologies are state Standard R 57558-2017 / ISO / ASTM 52900: 2015 Additive manufacturing processes. Basic principle. Part 1. Terms and definitions, which contains definitions of 3D printing, 3D printer, and state Standard R 57563-2017 / ISO / TS 12911: 2012 information Modeling in construction. The main provisions for the development of standards for information modeling of buildings and structures include the concept of an information model.

An information model is defined as an object-oriented parametric 3D model that digitally represents the physical, functional, and other characteristics of an object (or its individual parts) as a set of information-rich elements. However, this document does not contain the concept of a 3D model.

State Standard R 57590-2017. Additive manufacturing processes. General requirements defines the concept of 3D CAD modeling as the process most commonly used in design to create a digital 3D model. The starting point can be an image of a product that takes shape and becomes more and more defined directly on the computer screen, or a previously created image of an object in the form of sketches, drawings, etc., which are then simply converted to 3D data. The product volume can be described using two different methods or a combination of both. An object consists of either elementary volumes (shapes) (for example, a rectangular parallelepiped. a cylinder, cone, sphere, etc.) that generate a real object using a sequence of logical operations, or a volume that describes its neighborhood of boundary surfaces and the location of materials relative to boundary surfaces.

10 Zakharova MI (2019) Legal regulation of a 3D document and its application in the business environment. Intellectual property in the modern world, pp. 91-93 
State Standard R 57591-2017. "Additive manufacturing processes. Data processing " contains an extremely concise definition of 3D-three-dimensional design, which does not reveal its features.

Typically, a detailed definition of 3D can be found in local documents of organizations involved in modeling, design, and so on. Such definitions may also be contained in technical specifications and other appendices to contracts.

For an electronic document management system with 3D participation, the concept of a Common Data environment $(\mathrm{CDE})$ as a single source of reliable information for all project participants can be useful. $\mathrm{CDE}$ is based on procedures and regulations that effectively manage the iterative process of developing an information model and issuing project documentation to achieve full integration and spatial coordination of data/information from all participants and sources of this information.

An electronic document is any text, sound, image, or other electronic information stored in the original format for the application in which it was created.

The absence of such definitions in regulatory legal acts gives rise to discrepancies in the definition of the same concepts, and therefore it is advisable to Supplement Article 3 state Standard R 7.0.97-2016. National standard of the Russian Federation. System of standards for information, library and publishing. Organizational and administrative documentation. Requirements for the design of documents with definitions for certain types of electronic documents, including 3D.

It is necessary to develop a separate state standard dedicated to the direct creation of $3 \mathrm{D}$ documents, which would resolve all technical issues and problems of the conceptual apparatus.

First of all, it is necessary to develop a General definition of a 3D document based on the terms discussed earlier, namely: "a 3D document is an electronic document containing a representation of the geometry of objects and their location in space (in X, Y and Z coordinates)".

Separately, the concepts of 3D models can be introduced as images of an object, its geometry and location in space (in X, Y, and Z coordinates), BIM, or an information model for construction and design purposes. The latter can be understood as a digital representation of the physical and functional characteristics of an object through a set of elements and information about the design, construction, operation, modernization and demolition of a construction object. It may be appropriate to introduce the concepts of 3D models obtained using different technologies, as well as requirements for the format and quality of created $3 \mathrm{D}$ documents.

The development of technologies inevitably leads to the introduction of $3 \mathrm{D}$ documents in almost all areas of human activity. 3D modeling has become a unique tool that allows you to create 
a wide variety of objects, from simple models of geometric shapes to human organs.

In conclusion, it is worth noting that today cadastral registration is still carried out based on a two-dimensional map. In Russia, although separate projects are being developed for the threedimensional representation of spatial objects and the creation of 3D models of cities, a unified system has not yet been created due to the lack of the necessary legal framework.

The capabilities of the three-dimensional cadastre contain a huge potential for managing the development of territories by state and local authorities, as well as planning and controlling the production of many economic works, such as construction, laying communications, and repair work in the housing and communal services system.

The current stage of development of land relations without significant changes in the field of real estate cadastre, land management and land management, innovative activities both in Russia and abroad cannot be carried out at the required pace.

The research conducted in the article allows us to come to the conclusion that it is necessary to create a framework for regulating 3D documents in Russian legislation. Further development of this Institute is necessary. To work on improving legislation in the field of $3 \mathrm{D}$ documents, it is necessary to involve not only interested state bodies and departments, but also technical specialists, including for the development of state standards.

\section{References}

Baturin YuM, Eremchenko EN, Zakharova MI (2019) 3D-document and Digital Earth. CEUR Workshop Proceedings. Vol. 2485. pp. 155-158.

Deeva AK, Shirina NV (2016) Three-Dimensional cadastre in the Russian Federation (Russian). Student scientific forum. Belgorod state technological University named after V. G. Shukhov.

Eremchenko EN, Tikunov VS (2016) Holographic visualization capabilities in geography (Russian). Bulletin of the Moscow University. Series 5: Geography. N. 2. pp. 22-29.

Eremchenko E, Tikunov V, Nikonov O, Moroz V, Massel L, Zakharova A, Dmitrieva V, Panin A (2017) Digital Earth and digital economy (Russian) Geocontext. No5. T. 5. pp. 48-57

Kalacheva NI (2013) Application of the 3-D cadastre with a time component in land and property relations of road management (Russian). CAD and GIS. 1, pp. 67-69.

Leonov AV, Baturin YuM (2014) 3D Document - a new type of scientific and technical 
documentation (Russian). Bulletin of the Archivist, N 2. pp. 192-205.

Nikolaeva TV, Nikitin VN (2014) Cadastre in 3d format (Russian). Interexpo Geo-Siberia. Vol. 2. pp. 199-204.

Pavlova EA (2012) Development of three-dimensional cadastre of real estate objects in Russia. Young scientist. 8 (43) , 40-42

Zakharova MI (2019) Legal regulation of a $3 D$ document and its application in the business environment. Intellectual property in the modern world, pp. 91-93 